UDC 316.776:159.923:331.548

LBC 60.53

\title{
FRAMING OF THE SUBJECTIVE ATTITUDE TO THE ACQUIRED COMPETENCIES OF HELPING PROFESSIONS IN THE EDUCATIONAL ENVIRONMENT OF THE UNIVERSITY
}

\author{
Olga I. Shutova \\ Volgograd State Medical University, Volgograd, Russian Federation
}

\begin{abstract}
Annotation. This article presents the research results of the dynamic of the formation of a person subjective attitude to supporting specialists' competencies in the educational environment of a university. The relevance of the study is due, on the one hand, to insufficient knowledge of the concept of "educational environment", its structure, correlation with other concepts, such as a multicultural environment, professional competencies. On the other hand, the study of the psychology of competencies and their structure, specificity (on the example of a specific group of professions), diagnostics, psychological and pedagogical conditions of formation. The practical significance of the study lies in examining professional competencies through the personal components of students, which are the subjective attitude of the individual. Empirical research was based on the use of quantitative data collection methods that reveal the concept of a person's subjective attitude. The sample consisted of 140 students of the faculties of "General Medicine" and "Social Work and Clinical Psychology" of The Volgograd State Medical University, who were trained in the second (2016) and fourth year (2018). The assessment of the attitude of students to the content of professional competencies of supporting specialists was measured using the author's methodology based on a list of general cultural and professional competencies declared in educational standards and selected by the subjects in accordance with the basic principles and rules of conducting a diagnostic study. The data obtained is processed through descriptive statistics. As a result, the structure and content of the subjective attitude of the individual was described, which includes the motivational ("important"), operational ("own") and pragmatic ("use") aspects of competencies. The course of study, the emerging "motivational stress", the organized conditions of the educational environment, involvement in practical professional activity determine the structure of the subjective attitude of students to the competencies being mastered: the structure of the second course of study is presented as "the motivational aspect - the operational aspect - the pragmatic aspect" of competencies, the structure of the fourth course of study - "pragmatic aspect - operational aspect - motivational aspect" of competencies. The choice of various psychological and pedagogical technologies in the training of specialists in helping professions as one of the effective conditions of the educational environment is aimed at manifesting, on the one hand, the cognitive activity of students, on the other, the formation of a positive attitude towards mastering a set of competencies. Information technologies and technologies for the development of critical thinking are aimed at developing research competencies. Interactive technologies of imitation and discussion types contribute to the development of a communicative group of competencies of supporting specialists, as well as conducting joint classes of Russian and foreign students, implementing patronage cooperation, etc. The results obtained can be taken into account in the practice of psychological, professional and socio-cultural support and adaptation of foreign and Russian students to supporting professions.
\end{abstract}

Key words: competencies, subjective attitude, educational environment, supporting professions, tolerance, conflict, communication.

Citation. Shutova O.I. Framing of the Subjective Attitude to the Acquired Competencies of Helping Professions in the Educational Environment of the University. Logos et Praxis, 2021, vol. 20, no. 1, pp. 100-108. (in Russian). DOI: https://doi.org/10.15688/lp.jvolsu.2021.1.11 


\title{
ФОРМИРОВАНИЕ СУБЪЕКТИВНОГО ОТНОШЕНИЯ ЛИЧНОСТИ К ОСВАИВАЕМЫМ КОМПЕТЕНЦИЯМ ПРОФЕССИЙ ПОМОГАЮЩЕГО ТИПА В ОБРАЗОВАТЕЛЬНОЙ СРЕДЕ ВУЗА
}

\author{
Ольга Игоревна Шутова \\ Волгоградский государственный медицинский университет, г. Волгоград, Российская Федерация
}

\begin{abstract}
Аннотация. В настоящей статье представлены результаты исследования динамики формирования субъективного отношения личности к осваиваемым компетенциям помогающих специалистов в образовательной среде вуза. Актуальность исследования обусловлена, с одной стороны, недостаточной изученностью понятия «образовательная среда», ее структурой, соотношением с другими понятиями, такими как поликультурная среда, профессиональные компетенции. С другой стороны, изучением психологии компетенций и их структуры, специфики (на примере конкретной группы профессий), диагностики, психолого-педагогических условий формирования. Практическая значимость исследования заключается в рассмотрении профессиональных компетенций посредством личностных компонент обучающихся, в качестве которых выступает субъективное отношение личности. Эмпирическое исследование базировалось на применении количественных методов сбора данных, раскрывающих понятие субъективное отношение личности. Выборка составила 140 обучающихся факультетов «Лечебное дело» и «Социальная работа и клиническая психология» ВолгГМУ, проходивших обучение на втором (2016 г.) и четвертом курсе (2018 г). Оценка отношения обучающихся к содержанию профессиональных компетенций помогающих специалистов была измерена с помощью авторской методики, основанной на списке общекультурных и профессиональных компетенций, заявленных в образовательных стандартах и отобранных испытуемыми в соответствии с основными принципами и правилами проведения диагностического исследования. Полученные данные обработаны посредством описательной статистики. В результате была описана структура и содержание субъективного отношения личности, которая включает мотивационный («важно»), операциональный («владею») и прагматический («использую) аспекты компетенций. Курс обучения, возникающее «мотивационное напряжение», организованные условия образовательные среды, приобщенность к практической профессиональной деятельности определяют структуру субъективного отношения обучающихся к осваиваемым компетенциям: структура второго курса обучения представлена как «мотивационный аспект - операциональный аспект - прагматический аспект» компетенций, структура четвертого курса обучения - «прагматический аспект - операциональный аспект - мотивационный аспект» компетенций. Выбор различных психолого-педагогических технологий при обучении специалистов помогающих профессий как одно из эффективных условий образовательной среды направлен на проявление, с одной стороны, познавательной активности обучающихся, с другой, формирование позитивного отношения к освоению набора компетенций. Информационные технологии и технологии развития критического мышления направлены на освоение научно-исследовательских компетенций. Интерактивные технологии имитационного и дискуссионного типов способствуют развитию коммуникативной группы компетенций помогающих специалистов, а также проведение совместных занятий российских и иностранных обучающихся, осуществление патронажного сотрудничества и др. Полученные результаты могут быть учтены в практике психологического, профессионального и социокультурного сопровождения и адаптации иностранных и российских обучающихся помогающим профессиям.
\end{abstract}

Ключевые слова: компетенции, субъективное отношение, образовательная среда, помогающие профессии, толерантность, конфликт, коммуникация.

Цитирование. Шутова О. И. Формирование субъективного отношения личности к осваиваемым компетенциям профессий помогающего типа в образовательной среде вуза // Logos et Praxis. - 2021. - Т. 20, № 1. -C. 100-108. -DOI: https://doi.org/10.15688/lp.jvolsu.2021.1.11

Одной из важных тем обсуждения в сфере науки и технологий является изучение понятия образовательной среды (Г.Ю. Беляев, О.В. Гукаленко, В.Н. Пустовойтов, В.И. Сло- бодчиков, В.А. Ясвин и др.) [Гукаленко, Пустовойтов 2017]. Согласно В.А. Адольф, Ю.В. Ананьиной, В.И. Блинову, Е.В. Васильевой, образовательная среда понимается как 
система условий, которая обеспечивает наиболее оптимальные параметры образовательной деятельности в различных ее аспектах (целевом, процессуальном, содержательном, результативном, ресурсном) и выступающая эффективным средством формирования профессиональной компетентности в процессе обучения в профессиональном образовательном учреждении [Слепцова 2017]. Она способствует формированию «...политолерантности личности...» [Михайлова web], повышению коммуникативной компетентности (М. Имай, Дж. Канеро, Д. Коестер, Д. Лью, М.В. Лустиг, Т. Масуда, Ф. Фанг) [Imai, Kanero, Masuda 2016; Koester, Lusting 2015; Liu, Fang 2017], ee профессионального саморазвития [Сибаева, Тлявсина web] и идентификации с выбранной профессией (Ф. Аташзадеш-Шуридех, С. Годсей, М.А. Галеноэ, Ф. Фаргинфард, Д. Мохташами, Х. Рахмама, А. Талеби) [Mohtashami et al. 2015; Godsey 2011], освоению профессиональных умений, навыков, качеств и ценностей профессии с учетом регионального компонента. В.В. Гладких в контексте поликультурной среды описывает внутренние компоненты образовательной среды, такие как обучающий, воспитывающий, развивающий [Гладких 2011]. Автор также отмечает важность формирования открытости личности к иным культурным ценностям, уважительное и толерантное отношение к представителям иного образа жизни и поведения, видение в культурном многообразии источника для взаимообогащения и взаиморазвития, готовность участвовать в разрешении конфликтов [Гладких web]. Схожие требования можно проследить в наборе профессиональных компетенцией представителей профессии помогающего типа, представленных в ФГОС ВО 3++.

При более детальном их рассмотрении возникают вопросы отсутствия единой теоретической базы для разработки научных проблем компетенций (Т.В. Черникова) [Черникова 2013], а именно их реализации с учетом содержания образовательных стандартов (Э.Ф. Зеер) [Зеер, Сыманюк 2005], разработки лаконичного и понятного набора компетенций (А.В. Хуторской) [Хуторской 2020], отсутствия валидных диагностических методов измерения компетенций (Е.А. Климов,
А.К. Маркова) [Климов 2014], подбора эффективных технологий и средств обучения (А.И. Артюхина, Э.Ф. Зеер, Т.В. Черникова, В.И. Чумаков) [Куликов, Артюхина, Чумаков 2016; Климов 2014; Черникова 2019], учет личностной составляющей компетенций обучающихся (Т.Ю. Базаров) [Ерофеев, Базаров 2014]. Особое внимание хотелось бы уделить личностному фактору освоения компетенций, так как именно он обуславливает процесс освоения компетенций, определяет наличие учебной активности обучающихся, формирует субъективное отношение к усваиваемым знаниям и социокультурного контекста. Изучение особенностей освоения профессиональных компетенций представителей профессий помогающего типа сферы здравоохранения раскрывается в специфике профессий данной группы (врачи, психологи, клинические психологи, специалисты социальной работы и т. д.). Помогающий специалист выступает одновременно «инструментом» и «средством» оказания помогающей помощи. К нему предъявляются высокие требования личностного (стремление к самосовершенствованию, саморазвитию, реализации своего личностного потенциала, наличие эмпатии, развитые коммуникативные навыки, толерантность и т. д.) и профессионального характера (стремление к реализации своего профессионального потенциала, постоянный рост и развитие, наличие критичности к себе, умение координировать деятельность различных специалистов и учреждений, знание иностранных языков и т. д.).

Таким образом, целью исследования является выявление особенностей формирования субъективного отношения личности к осваиваемым компетенциям профессий помогающего типа на различных этапах обучения в вузе. Базой исследования выступил ВолгГМУ. Выборка составила 140 человек, обучающиеся на факультетах «Лечебное дело», «Социальная работа и клиническая психология», которые участвовали в опросе дважды, проходя обучение на втором (2016 г.) и четвертых (2018 г.) курсах. Отметим, что под эффективными условиями образовательной среды медицинского вуза в настоящем исследовании понимается психолого-педагогические технологии обучения, воспитания и развития личности. 
Нами была разработана методика оценки отношения обучающихся к содержанию профессиональных компетенций представителей помогающих профессий. Был составлен список из 30 общекультурных и профессиональных компетенций, таких как «быть толерантным к людям», «способность к разрешению конфликтов в коллективе», «быть готовым к координации деятельности различных организаций, учреждений и предприятий, специалистов в решении задач оказания помощи», «быть способным учитывать специфику различных национальных, половозрастных и социально-классовых групп в своей работе» и др. В качестве теоретических положений разработки инструментария выступали идеи об активности (Ю.П. Поваренков) и ее внутренней организации (Дж. Келли, А.В. Петровский, М.Г. Ярошевский), субъективных представлениях личности как результате ее активности (А.Н. Леонтьев, С.Л. Рубинштейн, М.М. Кашапов); в качестве методологических положений: принцип целенаправленности и цикличности исследования (А.Ю. Чернов), принцип репрезентативности выборки, принцип «предельного насыщения»; диагностический инструментарий включал опрос.

Во время проведения опроса респондентам предоставлялась одинаковая инструкция, согласно которой необходимо было выразить свое отношение к предъявленному набору компетенций по семибалльной шкале (от 1 до 7) три раза. Во время первого заполнения необходимо было оценить, насколько компетенции важны для респондентов, во время второго насколько они владеют ими, в третий раз как часто они их используют. Соответственно, чем важнее компетенция и чем в большей мере респонденты ею владеют по своим собственным субъективным ощущениям, тем выше должен быть балл.

Методика соответствует требованиям валидного и надежного инструмента, что было подтверждено в результате проведения пилотажного исследования (выборка составила 60 человек, исследование проводилось в 2015 г). Надежность опросника подтверждалась путем расщепления выборки на две равные части, коэффициент Кронбаха составлял $\alpha=0,83$. Внутренняя валидность опросника определялась как согласованность оценок, ко- торые были получены для всех трех шкал в результате проведенного корреляционного анализа (мотивационный аспект - операциональный аспект $r=0,021$ (при $p>0,1$ ), мотивационный аспект - прагматический аспект $\mathrm{r}=0,043$ (при $\mathrm{p}>0,1)$, операциональный аспект - прагматический аспект $\mathrm{r}=-0,011$ (при $\mathrm{p}>0,1)$ ). Отсутствие статистически достоверной и сильной связи между значениями переменных позволяет утверждать о наличии согласованности шкал и о внутренней валидности опросника.

Охарактеризуем подробнее различные аспекты субъективного отношения респондентов к осваиваемым компетенциям профессий помогающего типа:

Мотиваиионный аспект (или насколько «важно») субъективного отношения респондентов к осваиваемым компетенциям включает компоненты познавательной активности личности, которые проявляются в осознанном и целенаправленном саморегулировании учебной или профессиональной деятельности.

Операциональный аспект (или насколько «владею») субъективного отношения респондентов к осваиваемым компетенциям характеризуется осознанием целей, средств и задач, которые будут способствовать эффективной профессионализации.

Прагматический аспект (или как часто «использую») субъективного отношения респондентов к осваиваемым компетенциям раскрывает смысловую нагрузку учебной или профессиональной активности личности, а также выявляет причины, по которым студент затрачивает усилия, соотносящиеся с поиском и использованием необходимой информации.

В результате для каждого изучаемого параметра была рассчитана суммарная оценка отношения отобранных респондентами компетенций к общему количеству отобранных в методике компетенций. Так, в целом по выборке обучающихся на втором курсе были получены следующие результаты, представленные в таблице 1 .

Для подтверждения статистически достоверных различий между полученными значениями был применен Т-критерий Стьюдента для независимых выборок, результаты представлены в таблице 2. 
Данные свидетельствуют о наличии статистически достоверных различий в средних оценках респондентами второго курса обучения различных аспектов изучаемых компетенций.

Наибольшие средние значения были получены у параметра «мотивационный аспект компетенций» («важно»), значение которого $\mathrm{x}=8,99$. Далее параметры «операциональный аспект компетенций» («владею») и «прагматический аспект компетенций» («использую») имеют значения $\mathrm{x}=8,06$ и $\mathrm{x}=7,09$ соответственно. Полученные различия между переменными являются статистически достоверными и значимыми. На основании этого можно полагать, что субъективное отношение к различным аспектам осваиваемых компетенций можно представить в виде определенной иерархии, которая будет представлена следующим образом: «важно» - «владею» - «использую». По нашему мнению, полученная в результате исследования иерархия в содержательном плане будет отражать внутреннюю согласованность различных аспектов осваиваемых компетенций (мотивационный, операциональный и прагматический).

При этом стоит отметить, как достоверные на статистическом уровне значимости различия средних значений, так и достоверные различия с их относительной величиной. Среди средних значений показателей пары «мотивационный аспект компетенций - прагматический аспект компетенций» $(\mathrm{T}=9,89)$ выявлен значимый «разрыв», что дает основание полагать, что положительная мотива- ционная значимость компетенции не обязательно будет совпадать $\mathrm{c}$ ее прагматической оценкой. Между переменными пары «операциональный аспект компетенций - мотивационный аспект компетенций» также был отмечен определенный «дисбаланс» $(\mathrm{T}=-5,08)$, где положительная мотивационная значимость компетенции не соответствует ее операциональной оценке, то есть важность освоения компетенции не означает факт того, насколько ею владеет личность. Схожие выводы можно проследить при рассмотрении пары переменных «операциональный аспект компетенций - прагматический аспект компетенций», где достоверность различий средних значений составляет $\mathrm{T}=4,86$.

На четвертом курсе обучения респонденты повторно приняли участие в опросе. Результаты суммарной оценки отношения к отобранным компетенциям представлены в таблице 3.

С целью подтверждения статистически достоверных различий между полученными значениями был применен Т-критерий для независимых выборок, результаты представлены в таблице 4.

Приведенные данные свидетельствуют об изменении структуры субъективного отношения личности к осваиваемым компетенциям в зависимости от курса обучения. Наибольшие средние значения были получены у параметра «прагматический аспект компетенций» («использую»), значение которого $\mathrm{x}=9,56$. Далее параметры «операциональный аспект компетенций» («владею») и «мотива-

Таблица 1

Средние значения и дисперсия результатов оценки компетенций по параметрам «владею», «важно», «использую» (2-й курс обучения)

\begin{tabular}{|l|c|c|}
\hline \multicolumn{1}{|c|}{ Параметры оценки аспектов компетенций } & Среднее значение & Дисперсия \\
\hline Операциональный аспект компетенций & 8,0628 &, 98565 \\
\hline Мотивационный аспект компетенций & 8,9856 &, 80785 \\
\hline Прагматический аспект компетенций & 7,0923 &, 83589 \\
\hline
\end{tabular}

Таблица 2

Достоверность различий средних значений параметров «владею», «использую» и «важно» (2-й курс обучения) (при р $=0,000)$

\begin{tabular}{|l|c|}
\hline \multicolumn{1}{|c|}{ Параметры оценки компетенций } & T \\
\hline Мотивационный аспект компетенций - Прагматический аспект компетенций & 9,888 \\
\hline Операциональный аспект компетенций - Прагматический аспект компетенций & 4,865 \\
\hline Операциональный аспект компетенций - Мотивационный аспект компетенций & $-5,082$ \\
\hline
\end{tabular}


ционный аспект компетенций» («важно») имеют значения $\mathrm{x}=8,05$ и $\mathrm{x}=6,96$ соответственно. Субъективное отношение к различным аспектам осваиваемых компетенций на старших курсах обучения имеет следующую иерархию: «использую» - «владею» - «важно», что отражает значимость для обучающихся на старших курсах обучения того, на сколько часто они могут использовать осваиваемую компетенцию. Полученная иерархия противоположна структуре субъективного отношения обучающихся на втором курсе.

На основании результатов опроса респондентов различных этапов обучения в вузе, можно сделать следующие выводы: на первичных этапах обучения различная оценка сторон компетенций обучающимися помогающим профессиям свидетельствует о наличии необходимого в данном случае мотивационного напряжения. Полагаем, что вектор выявленного мотивационного напряжения направлен от осознания важности компетенции через осознанное владение ей к осознанию ее конкретной практической ценности. В данном случае возникающее мотивационное напряжение выступает основой формирования отношения к осваиваемым компетенциям. Как следствие выявленного обстоятельства, сближение оценок или их совпадение, произойдет в ходе осуществления практической профессиональной деятельности, в процессе которой помогающий специалист будет совершенствовать умения, навыки и видеть конкретные результаты своих усилий. Позитивное формальное отношение к компетенции со стороны обу- чающегося не будет означать принятия и использования им ее как важного условия эффективного осуществления профессиональной деятельности. Полагаем, что различные психолого-педагогические технологии будут способствовать наиболее эффективному овладению обучающимися различными компетенциями. Например, применение интерактивных технологий эвристического типа, технологий развития критического мышления, исследовательские и информационные технологии, по нашему мнению, будут способствовать освоению научно-исследовательских компетенций и проявлению активности, самостоятельности личности. Под интерактивными технологиями обучения эвристического типа мы понимаем те образовательные технологии, которые направлены на познание, профессионально-личностное развитие обучающегося, поиск им истины посредством ее открытия в процессе сотрудничества. Реализации данных задач соответствуют синектические методы, выполнение различных проектов и в том числе междисциплинарных, овладение и внедрение в деятельность методов и методик других наук. Развитию коммуникативных компетенций как одних из основополагающих компетенций и детерминирующих эффективность помогающей деятельности будут способствовать интерактивные технологии обучения имитационного (мозговой штурм, решение различных ситуационных задач или обсуждение конкретных кейсов) и дискуссионного типов (проведение тематических круглых столов, побуждение обучающихся к участию в учебной дис-

Средние значения и дисперсия результатов оценки компетенций по параметрам «владею», «важно», «использую» (4-й курс обучения)

\begin{tabular}{|l|c|c|}
\hline \multicolumn{1}{|c|}{ Параметры оценки аспектов компетенций } & Среднее значение & Дисперсия \\
\hline Прагматический аспект компетенций & 9,5648 &, 79566 \\
\hline Операциональный аспект компетенций & 8,0586 &, 78085 \\
\hline Мотивационный аспект компетенций & 6,9623 &, 63549 \\
\hline
\end{tabular}

Таблица 3

\section{Таблица 3}

\section{Таблица 4}

\section{Достоверность различий средних значений параметров «владею», «использую» и «важно» (4-й курс обучения) (при р $=0,000)$}

\begin{tabular}{|l|c|}
\hline \multicolumn{1}{|c|}{ Параметры оценки компетенций } & T \\
\hline Прагматический аспект компетенций - Мотивационный аспект компетенций & 8,783 \\
\hline Операциональный аспект компетенций - Прагматический аспект компетенций & 7,685 \\
\hline Операциональный аспект компетенций - Мотивационный аспект компетенций & 4,899 \\
\hline
\end{tabular}


куссии с преподавателем-ведущим, со студентом-ведущим, без ведущего, в форме «судебных заседаний», «форума», «заседания экспертной группы», парной, звеньевой, бригадной и др.). Наиболее актуальными технологиями в контексте активизации образовательной среды вуза являются: проведение совместных занятий с обучающимися российских и иностранных отделений, осуществление патронажного сотрудничества, а также участие обучающихся в международных праздниках. Данные технологии также направлены на формирование позитивного отношения к освоению компетенций, связанных с оказанием помощи людям различных национальностей и социальных групп, проявление толерантности в работе. Такие технологии способствуют формированию зрелой, осознанной профессиональной позиции будущего специалиста помогающей профессии.

\section{СПИСОК ЛИТЕРАТУРЫ}

Гладких 2011 - Гладких В.В. Гражданско-патриотическое воспитание молодежи в поликультурной среде вуза: системно-деятельностный подход : дис. ... д-ра пед. наук. Тамбов, 2011. 436 с.

Гладких web - Гладких В.В. Сущность и особенности формирования поликультурной информационной среды учреждения образования // Вестник ТГУ. Серия: Гуманитарные науки. 2010. № 12 (92). C. 41-46// https://cyber leninka.ru/article/n/suschnost-i-osobennostiformirovaniya-polikulturnoy-informatsionnoysredy-uchrezhdeniya-obrazovaniya (дата обращения: 21.03.2020).

Гукаленко, Пустовойтов 2017 - Гукаленко О.В., Пустовойтов В.Н. Поликультурное образовательное пространство как среда обеспечения социально-педагогической безопасности молодежи // Современные проблемы науки и образования. 2017. № 6 // http://www.scienceeducation.ru/ru/article/view?id=27331 (дата обращения: 09.03.2020).

Ерофеев, Базаров 2014 - Ерофеев А.К., Базаров Т.Ю. Авторские технологии разработки моделей компетенций // Организационная психология. 2014. № 4 // https://cyberleninka.ru/article/ n/avtorskie-tehnologii-razrabotki-modeleykompetentsiy (дата обращения: 21.03.2020).

Зеер, Сыманюк 2005 - Зеер Э.Ф., Сыманюк Э.Э. Компетентностный подход к модернизации профессионального образования // Высшее образование в России. 2005. № 4. С. 23-30.

Климов 2014 - Климов Е.А. Трудности и перспективы становления профессионала//Муниципальное образование: инновации и эксперимент. 2014. № 3. С. 48-53.

Куликов, Артюхина, Чумаков 2016 - Куликов В.С., Аpтюхина А.И., Чумаков В.И. Диагностика результативности педагогической технологии в непрерывном профессиональном образовании // Проблемы непрерывного профессионального образования в России: состояние и перспективы: материалы докл. VI Всерос. науч.-практ. конф. с международным участием. Ростов н/Д: Изд-во РостГМУ. 2016. С. 100-113.

Михайлова web - Михайлова Т.В. Поликультурная среда вуза: к вопросу о содержании понятия // [Материалы всероссийских педагогических чтений «Педагогическое наследие Степана Павловича Титова». Барнаул: АлтГПА. 2010. C. 320-322] // https://old.altspu.ru/titov/ sourcebook.

Сибаева, Тлявсина web-Сибаева Г.М., Тлявсина Г.А. Роль поликультурной образовательной среды в формировании профессиональных ценностей будущих педагогов-психологов // Международный журнал экспериментального образования. 2014. № 7 (ч. 1). С. 38-39// http:// www.expeducation.ru/ru/article/view?id $=5443$ (дата обращения: 26.08.2019).

Слепцова 2017 - Слепцяова М.В. Анализ содержания понятия «Поликультурная образовательная среда» // Профессиональное образование в России и за рубежом. 2017. № 3 (27) // https://cyberleninka.ru/article/n/analizsoderzhaniya-ponyatiya-polikulturnayaobrazovatelnaya-sreda (дата обращения: 12.08.2020).

Хуторской $2020-$ Хуторской А.В. Структура и содержание компетентностного учебника для вуза // Высшее образование сегодня. 2020. №. 1. Педагогика. С. 8-13.

Черникова 2019 - Черникова Т.В. Креативность и творчество: феномен и проблемы исследования // Теория и практика реализации творческого потенциала: монография / А.Б. Панькин (ред.). Элиста: Изд-во Калм. ун-та, 2019. C. 9-25.

Черникова 2013 - Черникова Т.В. От квалиметрии к развитию компетентности: динамика современных подходов к управлению качеством образования в вузе // Управление качеством образования в вузе: проблемы, перспективные идеи и технологии: материалы Междунар. науч. конф. Ч. 1 / Исламгулова С.К. (ред.). Алматы: Университет «Туран», 2013. С. 18-38. 
Godsey 2011 - Godsey S. Student perceptions of professional identity and cultural competence : in partial fulfillment ... doctor of education Duluth, 2011.

Imai, Kanero, Masuda 2016 - Imai M., Kanero J., Masuda T. The relation between language, culture, and thought // Current Opinion in Psychology. 2016. Vol. 8. P. 70-77.

Koester, Lusting 2015 - Koester J., Lustig M.W. Intercultural communication competence: Theory, measurement, and application // International Journal of Intercultural Relations. 2015. Vol. 48. P. 20-21.

Liu, Fang 2017 - Liu J., Fang F. Perceptions, awareness and perceived effects of home culture on intercultural communication: Perspectives of university students in China // System. 2017. Vol. 67. P. 25-37.

Mohtashami et al. 2015-Mohtashami J., Rahnama H., Farzinfard F., Talebi A., Atashzadeh-Shoorideh F., Ghalenoee M.A. Survey of Correlation between Professional Identity and Clinical Competency of Psychiatric Nurses // Open Journal of Nursing. 2015. №5. P. 765-772.

\section{REFERENCES}

Gladkikh V.V., 2011. Civil-patriotic education of youth in the multicultural environment of a university: a system-activity approach: dis. ... dr ped. sciences. Tambov. $436 \mathrm{p}$.

Gladkikh V.V., 2010. The essence and features of the formation of a multicultural information environment of an educational institution. Vestnik TGU. Series: Humanities, no. 12, pp. 4146. URL: https://cyberleninka.ru/article/n/ suschnost-i-osobennosti-formirovaniyapolikulturnoy-informatsionnoy-sredyuchrezhdeniya-obrazovaniya.

Gukalenko O.V., Pustovoytov V.N., 2017. Multicultural educational space as a medium for ensuring the socio-pedagogical safety of youth. Modern problems of science and education. Section: Pedagogical sciences, no. 6. URL: http:// www.science-education.ru/ru/article/ view?id=27331 (accessed 09 March 2020).

Zeyer E.F., Symanyuk E.E., 2005.Competency-based approach to the modernization of vocational education. Higher education in Russia, 2005, no. 4, pp. 23-30.

Klimov Ye.A., 2014. Difficulties and prospects of becoming a professional. Municipal education: innovation and experiment, no. 3, pp. 48-53.

Kulikov V.S., Artyukhina A.I., Chumakov V.I., 2016. Diagnostics of the effectiveness of pedagogical technology in continuing professional education. Problems of continuing professional education in Russia: state and prospects Proceedings of the VI All-Russian Scientific and Practical Conference with international participation. Rostov-on-Don, Publishing house RostGMU. P. 100-113.

Mikhaylova T.V. Multicultural environment of the university: to the question of the content of the concept. Materials of all-Russian pedagogical readings "Pedagogical heritage of Stepan Pavlovich Titov». Barnaul, AltGPA, 2010, pp. 320322. URL: https://old.altspu.ru/titov/sourcebook.

Sibayeva G.M., Tlyavsina G.A., 2014. The role of multicultural educational environment in the formation of professional values of future teachers-psychologists. International Journal of Experimental Education, no. 7-1, pp. 38-39. URL: http://www.expeducation.ru/ru/article/ view?id=5443 (accessed 26 August 2019).

Sleptsova M.V., 2017. Analysis of the content of the concept «Multicultural educational environment». Professional education in Russia and abroad, no. 3 (27). URL: https:// cyberleninka.ru/article/n/analiz-soderzhaniyaponyatiya-polikulturnaya-obrazovatelnayasreda (date accessed: 12.08.2020).

Khutorskoj A.V., 2020. Structure and Content of the Competent Textbook for the University. Higher Education Today, no. 1. Pedagogy, pp. 8-13.

Chernikova T.V., 2019. Creativity and creativity: the phenomenon and problems of research. Pan'kin A.B. (ed.). Theory and practice of realizing creative potential: monograph. Elista, Izd-vo Kalm. un-ta, pp. 9-25.

Chernikova T.V., 2013. From qualimetry to the development of competence: the dynamics of modern approaches to managing the quality of education at a university. Islamgulova S.K. (ed.). Management of the quality of education at the university: problems, promising ideas and technologies: Materials of the Intern. scientific conf. Part 1. Almaty, Turan University, pp. 18-38.

Godsey S., 2011. Student perceptions of professional identity and cultural competence: in partial fulfillment ... doctor of education. Duluth. 99 p.

Imai M., Kanero J., Masuda T., 2016. The relation between language, culture, and thought. Current Opinion in Psychology, vol. 8, pp. 70-77.

Koester J., Lustig M.W., 2015. Intercultural communication competence: Theory, measurement, and application. International Journal of Intercultural Relations, vol. 48, pp. 20-21.

Liu J., Fang F., 2017. Perceptions, awareness and perceived effects of home culture on intercultural communication: Perspectives of 


\section{СОЦИОЛОГИЯ И СОЦИАЛЬНЫЕ ТЕХНОЛОГИИ}

university students in China. System, vol. 67, pp. 25-37.

Mohtashami J., Rahnama H., Farzinfard F., Talebi A.,

Atashzadeh-Shoorideh F., Ghalenoee M.A.,
2015. Survey of Correlation between Professional Identity and Clinical Competency of Psychiatric Nurses. Open Journal of Nursing, no. 5, pp. 765-772.

\section{Information About the Author}

Olga I. Shutova, Candidate of Sciences (Psychology), Associate Professor, Department of General and Clinical Psychology, Volgograd State Medical University, Pavshikh Bortsov Sq., 1, 400131 Volgograd, Russian Federation, post@volgmed.ru, https://www.volgmed.ru, https://orcid.org/0000-0003-4907-9584

\section{Информация об авторе}

Ольга Игоревна Шутова, кандидат психологических наук, доцент кафедры общей и клинической психологии, Волгоградский государственный медицинский университет, площадь Павших Борцов, 1, 400131 г. Волгоград, Российская Федерация, post@volgmed.ru, https://www.volgmed.ru, https://orcid.org/0000-0003-4907-9584 